\title{
Breed effect and non-genetic factors affecting growth performance of sheep in a semi-arid region of Nigeria
}

\author{
O.M. Momoh", E.A. Rotimi and N.I. Dim \\ Department of Animal Breeding and Physiology, University of Agriculture, Makurdi \\ Nigeria \\ *Correspondence author: mykemomoh@gmail.com; +234-7036705073 \\ Original submitted in on $15^{\text {th }}$ May 2013 Published online at www.m.elewa.org on 30 th July 2013. \\ https://dx.doi.org/10.4314/jab.v67i0.95053
}

\begin{abstract}
Objective: This study was conducted to investigate the effects of breed and some non-genetic factors on growth performance of Balami and Uda sheep in a semi-arid region of Nigeria.

Methodology and results: Data on birth weight (BWT), 90-day weaning weight (90-DWWT), 6-month weight (6-MWT), 9-month weight (9-MWT) and yearling weight (Y-WT) of 595 lambs (306 Balami and 209 Uda) born in the Sheep Meat Project of the Federal Livestock Department (FLD), Katsina, between 1996 and 1998 inclusive were collected and used for this study. Pre and post weaning weight gains were also estimated on each lamb. Data was subjected to analysis of variance using the generalized linear model (GLM) procedure of SAS to determine the effects of breed, parity, sex, type of birth, season of birth and year of birth on the growth of lambs. Breed and sex significantly $(P<0.05)$ affected body weights at all ages. Pre and post-weaning growth rates were significantly $(P<0.05)$ affected by all the factors examined except parity of dam and year of birth. Significantly low to moderate phenotypic correlations were observed between the growth traits studied.

Conclusion and application of findings: Most of the non-genetic factors have been shown to be important sources of variation in the growth performance of sheep. Therefore, effects of environmental factors need to be corrected for if mixed model approaches such as the Best Linear Unbiased Prediction (BLUP) values are to be used for breeding value evaluation in Balami and Uda lambs.
\end{abstract}

Key words: Sheep, Balami, Uda, Pre and Post weaning growth, Sex, Parity.

\section{INTRODUCTION}

Sheep are widely distributed in Africa and in Nigeria; they are a major component of the livestock production system which is characterized by small flock sizes. They are found in different agro-ecological zones of Nigeria and constitute about 22 million of the total livestock population (R.I.M, 1992). Sheep occupy a special place in the rural economy of Nigeria, where they are not only emergency source of fund but also contribute significantly to raise animal protein intake profile for the average Nigerian. Uda and Balami breeds found in the semi-arid regions of Nigeria are the most abundant sheep breeds in the country. Choice of breeds for improving the output from sheep should depend on the amount of information available on them. Additionally, growth 
performance is a key production indicator as it has implications in the reproductive efficiency of sheep. Fast growth performance allows sheep to breed early and contribute more lambs in their lifetime. Fast growth rate entails reaching market weight early, which brings a quicker income to the farmer. The majority of the sheep population of the semiarid region of Nigeria is managed mainly under the traditional free-range system. Under this system of production, little or no information is available on factors affecting their productivity. For genetic progress, selection must be based on genetic merits instead of phenotype (Rashidi et al., 2008). Environmental factors such as age, sex, type of

\section{MATERIALS AND METHODS}

The data on birth weight, 90-day weaning weight, 6month body weight, 9-month body weight and yearling weight of 595 lambs (306 Balami and $209 \mathrm{Uda}$ ) born during 1996 to 1998 recorded at the Federal Livestock Department Sheep Meat Project Station, Katsina were utilized for this study. Pre-and post-weaning weight gains were estimated on each lamb. Katsina lies on latitude $13^{\circ} 01^{\prime} \mathrm{N}$ and longitude $07041^{\prime} \mathrm{E}$ with an altitude of $517 \mathrm{~m}$ above sea level and average annual precipitation of $416.30 \mathrm{~mm}$. The sheep were reared under semi-intensive system of management. They were grazed from 8.00 to 17.00 hours. In addition, ewes to be mated and those in early or late pregnancy were maintained on a concentrate supplement consisting of $25 \%$ cottonseed cake and $75 \%$ maize. The General Liner Model (GLM) procedure of the Statistical Analysis System (SAS, 2001) was used to analyze the data. Fixed effects evaluated for the growth traits were breed, (Uda, Balami), sex of lamb (male, female), parity of dam $(1,2,3)$, year of lambing (1996, 1997, 1998), type of birth (single, multiple) and season of birth (early rain, late rain, early dry, late dry)

\section{RESULTS AND DISCUSSION}

The least squares means and test of significance of the factors affecting body weight of sheep is presented in Table 1, while Table 2 presents the least squares means and test of significance of factors affecting the pre- and post-weaning growth rates of sheep in the study area. Breed effect was highly significant $(p<0.001)$, affecting lamb's body weight from birth to 6 birth and year of birth influence the estimation of breeding value. Investigation and determination of environmental factors that have effect on traits and correction of records for these factors cause estimated genetic parameters and breeding value to show animal's genetic potential (Rashidi et al., 2008). Therefore, the present investigation was carried out to study the effect of breed (Uda and Balami) and non-genetic factors (sex of lamb, parity of dam, year of lambing, type of birth and season of birth) on growth performance of lambs born under organized farm conditions of the Federal Livestock Department's Meat Project at Katsina in Katsina State, Nigeria.

seasons. The following fixed effect model was fitted to the data:

$Y_{i j k m n o}=\mu+B_{i}+S_{j}+P_{k}+Y_{i}+T_{m}+U_{n}+e_{e j i k l m n o}$

Where

$$
Y_{i j k m n o}=\text { Single observation. }
$$

$\mu=$ Overall mean

$B_{i}=$ Fixed effect of the $i^{\text {th }}$ breed $(i=1,2)$

$S_{j}=$ Fixed effect of the $j^{j \text { th }} \operatorname{sex}$ of $\operatorname{lamb}(j=1,2)$

$P_{k}=$ Fixed effect of the $k^{\text {th }}$ parity of dam $(k=1 \ldots 3)$

$Y_{i}=$ Fixed effect of the $\left.\right|^{\text {th }}$ year of birth $(I=1 \ldots 3)$

$T_{m}=$ Fixed effect of the $m^{\text {th }}$ type of birth $(m=1,2)$

$U_{n}=$ Fixed effect of the $n^{\text {th }}$ season of birth $(n=1 \ldots . .4)$

$\mathrm{e}_{\mathrm{ijk} k \mathrm{mno}}=$ Random residual error.

First order interactions were not considered.

The phenotypic correlations between the traits studied were investigated through the use of Pearson correlation coefficients.

months of age and $(p<0.01)$ from $9^{\text {th }}$ months to 12 months of age. The Balami breed demonstrated higher body weight at all stages than the Uda. Similarly, the Balami breed showed superiority $(p<0.01)$ at both preand post-weaning stages when compared to Uda (Table 2). These differences demonstrated breed effect. 
Table 1: Least squares means (+SE) and tests of significance of factors affecting body weight of sheep in Katsina, Nigeria.

\begin{tabular}{|c|c|c|c|c|c|c|}
\hline \multirow[b]{2}{*}{ Factor } & \multirow[b]{2}{*}{ No of Obs. } & \multicolumn{5}{|c|}{ Growth Traits (kg) } \\
\hline & & BWT & 90-D WWT & 6-MWT & 9-MWT & Y-WT \\
\hline $\begin{array}{l}\text { Overall } \\
\text { Breed }\end{array}$ & 595 & $\underset{* \star *}{3.34 \pm 0.03}$ & $\underset{* \star \star}{13.52 \pm 0.07}$ & $\underset{* \star \star}{20.29 \pm 0.09}$ & $\underset{* \star}{27.64 \pm 0.12}$ & $\underset{* *}{32.15 \pm 0.18}$ \\
\hline Balami & 306 & $3.55 \pm 0.04^{\mathrm{a}}$ & $13.89 \pm 0.09 a$ & $20.95 \pm 0,12^{a}$ & $27.81 \pm 0.19^{a}$ & $34.53 \pm 0.23^{a}$ \\
\hline Parity Uda & 289 & $\underset{* *}{3.11 \pm 0.04^{b}}$ & $\underset{*}{13.05 \pm 0.10^{b}}$ & $\begin{array}{c}19.51 \pm 0.12^{b} \\
N S\end{array}$ & $\begin{array}{c}27.36 \pm 0.15^{\mathrm{b}} \\
\mathrm{NS}\end{array}$ & $\underset{* *}{29.68 \pm 0.20^{b}}$ \\
\hline 1 & 224 & $3.05 \pm 0.05^{c}$ & $13.3 \pm 90.11 b$ & $19.55 \pm 0.14$ & $26.99 \pm 0.16$ & $30.53 \pm 0.26^{c}$ \\
\hline 2 & 180 & $3.33 \pm 0.05^{b}$ & $13.29 \pm 0.12 \mathrm{c}$ & $20.24 \pm 0.16$ & $27.60 \pm 0.20$ & $30.90 \pm 0.31^{b}$ \\
\hline Sex & 191 & $\underset{* * *}{3.64 \pm 0.04^{a}}$ & $\underset{\star 13.74 \pm 0.11^{a}}{a}$ & $\underset{* * \star}{21.08 \pm 0.15}$ & $\underset{* *}{28.28 \pm 0.26}$ & $\underset{* *}{35.25 \pm 0.26^{a}}$ \\
\hline Male & 309 & $3.52 \pm 0.03^{a}$ & $13.59 \pm 0.08 a$ & $20.37 \pm 0.12 a$ & $28.02 \pm 0.18$ & $33.27 \pm 0.24^{a}$ \\
\hline $\begin{array}{r}\text { Female } \\
\text { Type of Birth }\end{array}$ & 286 & $\underset{* \star *}{3.11 \pm 0.04^{b}}$ & $\underset{* \star \star}{13.34 \pm 0.10 b}$ & $\underset{* \star}{20.15 \pm 0.13 b}$ & $\begin{array}{c}27.08 \pm 0.16 \\
\text { NS }\end{array}$ & $\begin{array}{c}30.96 \pm 0.26^{b} \\
\text { NS }\end{array}$ \\
\hline Single & 353 & $3.3 \pm 60.03^{a}$ & $13.60 \pm 0.09 a$ & $20.60 \pm 0.11^{a}$ & $27.60 \pm 0.16$ & $30.90 \pm 0.24$ \\
\hline Multiple & 242 & $3.29 \pm 0.04^{b}$ & $13.29 \pm 0.10^{b}$ & $19.76 \pm 0.14^{b}$ & $28.28 \pm 0.19$ & $35.25 \pm 0.26$ \\
\hline Season of Birth & & ** & ** & NS & * & * \\
\hline Early dry & 152 & $3.03 \pm 0.06^{d}$ & $13.18 \pm 0.12^{d}$ & $19.16 \pm 0.11$ & $25.18 \pm 0.10^{d}$ & $30.91 \pm 0.30^{c}$ \\
\hline Late dry & 148 & $3.20 \pm 0.05^{c}$ & $13.20 \pm 0.13^{c}$ & $19.24 \pm 0.12$ & $25.15 \pm 0.09^{c}$ & $30.83 \pm 0.32^{d}$ \\
\hline Early wet & 124 & $3.60 \pm 0.05^{a}$ & $13.76 \pm 0.14^{b}$ & $23.16 \pm 0.16$ & $31.36 \pm 0.16^{a}$ & $35.23 \pm 0.38^{a}$ \\
\hline $\begin{array}{l}\text { Late wet } \\
\text { Year of birth }\end{array}$ & 171 & $\underset{* *}{3.49 \pm 0.05^{b}}$ & $\underset{* \star}{13.77 \pm 0.12^{\mathrm{a}}}$ & $\underset{* *}{20.31 \pm 0.13}$ & $\begin{array}{c}29.27 \pm 0.14^{b} \\
N S\end{array}$ & $\begin{array}{c}32.29 \pm 0.33^{b} \\
N S\end{array}$ \\
\hline 1996 & 225 & $3.39 \pm 0.05^{a}$ & $13.61 \pm 0.12^{b}$ & $20.29 \pm 0.14^{b}$ & $27.50 \pm 0.19$ & $32.13 \pm 0.29$ \\
\hline 1997 & 175 & $3.31 \pm 0.05^{b}$ & $13.64 \pm 0.11^{\mathrm{a}}$ & $20.64 \pm 0.17^{a}$ & $27.87 \pm 0.23$ & $32.69 \pm 0.34$ \\
\hline 1998 & 195 & $3.30 \pm 0.05^{c}$ & $13.18 \pm 0.10^{c}$ & $19.89 \pm 0.15^{c}$ & $27.37 \pm 0.22$ & $31.70 \pm 0.30$ \\
\hline
\end{tabular}

abcd $=$ means with different superscripts in the same column within subclass indicate significant differences * $P<0.05$, ${ }^{* *} P<0.01,{ }^{* \star *} P<0.001$, Ns $=$ Not significant $(P>0.05), N=$ No. of observations, BWT = body weight at birth, $90-$ DWWT = 90-day weaning weight, 6-MWT = 6-month body weight, 9-MWT = 9-month body weight, YWT $=$ yearling weight, SE = Standard error of mean.

Combella et al (1990) reported significant breed effect on live weight gains of sheep from birth to weaning. Taiwo et al, (1992) reported significant breed differences in post-weaning rate of gain in sheep. The results of the present study are consistent with these earlier reports. The mean birth weight and weights at other ages as well as pre- and post-weaning growth rates revealed that the male lambs showed superiority in growth than females. The sex of lamb had a highly significant $(P<0.001)$ effect on all growth traits, which were consistent from birth to yearling weight. Differences in sexual chromosomes, probably in the position of genes related to growth, physiological characteristics, difference in endocrinal system (type and measure of hormone secretion especially sexual hormones) lead to difference in animal growth. In relation to endocrinal system, estrogen hormone has a limited effect on the growth of long bones in females. That could be one of the reasons in which females have smaller body and lighter weight against males (Rashidi et al., 2008). Hafez (1962) has also ascribed sex effect on growth in farm animals to hormonal actions. Higher growth in prenatal stage under the influence of male hormones with anabolic effect (Hafex, 
1962) might be the reason for higher birth weight of male lambs. As the lambs grow, the males probably beginning to secret androgenic substances earlier grow and develop faster than the female (Ebangi et al., 1996).

Table 2: Least squares mean (+SE) and tests of significance of factors affecting pre- and post- weaning growth rate of sheep in Katsina, Nigeria.

\begin{tabular}{|c|c|c|c|c|c|}
\hline \multirow[b]{2}{*}{ Factor } & \multirow[b]{2}{*}{ No of Obs. } & \multicolumn{2}{|c|}{$\begin{array}{l}\text { Pre-weaning growth (Birth to } \\
\text { weaning) }\end{array}$} & \multicolumn{2}{|c|}{$\begin{array}{l}\text { Post-weaning growth (weaning to } \\
\qquad 12 \text { months) }\end{array}$} \\
\hline & & Total Gain & Avg Daily Gain & Total Gain & Avg Daily Gain \\
\hline Overall & 595 & $11.81 \pm 0.29$ & $0.07 \pm 0.21$ & $26.37 \pm 0.11$ & $0.13 \pm 0.14$ \\
\hline Breed & & $* *$ & ** & $\star *$ & * \\
\hline Balami & 306 & $12.45 \pm 0.31^{a}$ & $0.07 \pm 0.21 a$ & $28.31 \pm 0,09 a$ & $0.16 \pm 0.04 a$ \\
\hline Uda & 289 & $11.32 \pm 0.32^{b}$ & $0.06 \pm 0.22^{b}$ & $27.37+0.16^{b}$ & $0.14+0.04 b$ \\
\hline Parity & & NS & NS & $\overline{N S}$ & $\bar{N} S$ \\
\hline 1 & 224 & $11.06 \pm 0.09$ & $0.06 \pm 0.20$ & $26.74 \pm 0.12$ & $0.13 \pm 0.04$ \\
\hline 2 & 180 & $11.45 \pm 0.15$ & $0.06 \pm 0.19$ & $27.01 \pm 0.13$ & $0.14 \pm 0.20$ \\
\hline 3 & 191 & $12.25 \pm 0.19^{a}$ & $0.06 \pm 0.23^{a}$ & $28.09 \pm 0.10$ & $0.16 \pm 0.03$ \\
\hline Sex & & * & * & ** & * \\
\hline Male & 309 & $12.36 \pm 0.12^{\mathrm{a}}$ & $0.07 \pm 0.24^{a}$ & $28.39 \pm 0.09$ a & $0.14 \pm 0.04^{a}$ \\
\hline $\begin{array}{r}\text { Female } \\
\text { Type of Birth }\end{array}$ & 286 & $\underset{* \star}{11.81 \pm 0.18^{b}}$ & $\underset{*}{0.06 \pm 0.18 b}$ & $\underset{*}{27.77 \pm 0.08^{b}}$ & $\underset{*}{0.13 \pm 0.04 b}$ \\
\hline Single & 353 & $11.94 \pm 0.17^{a}$ & $0.07 \pm 0.20^{a}$ & $28.27 \pm 0.12^{a}$ & $0.15 \pm 0.05^{b}$ \\
\hline Multiple & 242 & $12.25 \pm 0.18^{a}$ & $0.06 \pm 0.20 b$ & $27.38 \pm 0.11^{b}$ & $0.13 \pm 0.04 b$ \\
\hline Season of Birth & & * & * & * & $* *$ \\
\hline Early dry & 152 & $11.46 \pm 0.17^{c}$ & $0.06 \pm 0.23^{b}$ & $28.41 \pm 0.09 \mathrm{a}$ & $0.14 \pm 0.04^{c}$ \\
\hline Late dry & 148 & $11.02 \pm 0.17^{d}$ & $0.06 \pm 0.23^{b}$ & $26.09 \pm 0.08^{d}$ & $0.13 \pm 0.04^{d}$ \\
\hline Early wet & 124 & $12.03 \pm 0.19 \mathrm{a}$ & $0.07 \pm 0.19 a$ & $28.40 \pm 0.11 \mathrm{a}$ & $0.16 \pm 0.04^{a}$ \\
\hline Late wet & 171 & $11.91 \pm 0.18^{b}$ & $0.07 \pm 0.22^{\mathrm{a}}$ & $27.39 \pm 0.13^{b}$ & $0.15 \pm 0.04^{b}$ \\
\hline Year of birth & & NS & NS & NS & NS \\
\hline 1996 & 225 & $12.65 \pm 0.17$ & $0.06 \pm 0.18$ & $26.57 \pm 0.13$ & $0.15 \pm 0.06$ \\
\hline 1997 & 175 & $12.04 \pm 0.16$ & $0.060 \pm .16$ & $25.30 \pm 0.18$ & $0.16 \pm 0.04$ \\
\hline 1998 & 195 & $12.25 \pm 0.16$ & $0.06 \pm 0.19$ & $27.69 \pm 0.14$ & $0.14 \pm 0.04$ \\
\hline
\end{tabular}

Parity of dam, type of birth, season and year of birth had variable influences on body weight (Table 1) and rate of growth at difference stages (Table 2). For instance, parity of dam was only significant $(P<0.01)$ in body weight at birth, and $(P<0.05)$ at weaning. Its influences on pre- and post-weaning growth rate were not significant $(P>0.05)$. This is in consonance with the reports of Wilson (1981) and Ebagi et al. (1996) who reported non-significant effect of parity of dam on lambs' body weights at 6 and 9 months of age and noted that the effect of parity of dam on lambs' performance up to weaning was more than in post weaning performance. In this study the significant effect of parity observed on yearling weight, which represent a deviation from earlier reports might be attributed to errors due to management practices and herdsman's skills.

Type of birth (single or multiple) had significant effects on birth weight, weaning $(P<0.01)$ and 6 -month body weight $(P<0.01)$ but no influence $(P>0.05)$ on 9 -month and yearling weights. The result of the effect of type of birth on growth parameters of sheep as obtained in this study is similar to the earlier findings of Nawaz and Khalil (1998) and Rastogi (2001), who reported 
significant effects of type of birth on lamb's weight at birth, weaning and 6 months of age. The birth weight advantage of single born lambs over the multiple born lambs may be due to competition for nutrient and uterine space. The multiple born lambs may have demonstrated compensatory growth after weaning. On pre and post-weaning growth rates, single born lambs exhibited superiority of growth over the multiple born lambs for the same reason advanced above.

Season and year of birth had similar influences $(P<0.01)$ on body weights at birth, weaning and 6 months of age. They had no influence $(P>0.05)$ on the 9 and 12-month weights of lamb. However, pre- and post-weaning growth rates were affected by season $(P<0.05)$ but not by year of birth $(P>0.05)$. Lambs born in the rainy season (early and late) were heavier at birth than those born in the dry season (early and late). In addition, lambs born in early rainy season were heavier, followed by those born in the late rainy season. This would have been possible due to the dry season supplementation of pregnant ewes with concentrate feed. Generally, Birth year causes vacillations over body weight in different ages by the effect of climatic condition (rate of rainfall, humidity and temperature), environmental and management conditions. Climate and environmental changes have effect on the quality and quantity of pasture forages, which also affect the provision of food and other requirements for animals. These changes in lambs have more effect on weaning traits and in their dams. The main effect will show on amount of milk production (increase or decrease). It has a direct influence on weaning weight and average daily gain from birth to weaning and has an indirect effect on birth weight due to changes in dam's environment and difference in feeding in the last weeks of pregnancy at different years. Differences in nutrition (especially during pregnancy), management and hygiene in the various years, are reasons for the effect of birth year on body weight in different ages (Hassan and Seyed, 2009)

Phenotypic Correlation between Body Weights: Table 3 presents the coefficients of phenotypic correlation between body weights of the two breeds combined.

Table 3: Coefficients of phenotypic correlation between body weights of Balami and Uda sheep in Katsina, Nigeria.

\begin{tabular}{|c|c|c|c|c|c|}
\hline Trait & BWT & 90-DWWT & 6-MWT & 9-MWT & Y-WT \\
\hline BWT & - & $0.28 * *$ & $0.27^{* *}$ & $0.31^{* *}$ & $0.33^{* *}$ \\
\hline 90-DWWT & & - & $0.15^{\star *}$ & $0.17^{* *}$ & $0.07^{* *}$ \\
\hline 6-MWT & & & - & $0.55^{* *}$ & $0.42^{* *}$ \\
\hline 9-MWT & & & & - & $0.40^{\star *}$ \\
\hline Y-WT & & & & & - \\
\hline
\end{tabular}

The phenotypic correlation coefficients were low to intermediate, except the relationship between 6-month weight and 9-month weight on one hand and 6-month weight on the other hand, which are high with respective coefficient values of 0.55 and 0.42 . The phenotypic correlation coefficient obtained between birth weight and weaning weight $(0.28)$, birth weight and 6-month weight $(0.27)$ and birth weight and 9month weight $(0.31)$ in the present study are higher than the respective values of $0.17,0.19$ and 0.14 reported by Hassan (1987) for Nigerian Yankasa sheep. Phenotypic correlation between two traits is the sum total of the genetic and environmental correlations. With appropriate design, the genetic correlation can be separated from the environmental and it is the genetic correlation that has real practical value for the Breeder. In this study, the genetic correlation could not be separated because enough pedigree information could not be obtained. The high phenotypic correlations between 6-month weight and those of 9-month and yearling weights indicated that 6 -month weight of $U d a$ and Balami sheep could be effective predictor of 9month and yearling weights.

\section{CONCLUSION AND RECOMMENDATION}


The results obtained in this study have demonstrated the importance of breed and non-genetic factors as sources of variation in body weight and growth rates of sheep. Type of birth, sex of lamb, season of birth and year of birth all influenced body weight and growth at

\section{REFERENCES}

Arora DN, Singh B, Kaira S, Balaine DS 1996 Studies on growth and body weights in different breeds of sheep. Livestock Adviser 11(11): 2931.

Cambella J, Martinaz N, Gonalez J 1990 Study of some factors affecting birth and weaning weights of lambs. Animal Breeding Abstract 48:

Ebangi AL, Nwakalor LN, Mba DA, Abba D 1996 Factors affecting the birth weight and neonatal mortality of Massa and Fulbe sheep breed in a hot and dry environment of Cameroon. Revue d'Élevage et de Medecine Vétérinaire des Pays Tropicaux 49:349-353.

Hafez EE. 1962 Reproduction in Farm Animals. (2 ${ }^{\text {nd }}$ edition). Lea and Febizer, Philadelphia.

Hassan WA. 1987 Genetic and environmental effects on the growth rate of Yankasa lambs. M.Sc. Ahmadu Bello University, Zaria. 161pp.

Hassan B and Seyed HH 2009 Effect of environmental factors on growth traits of Ghezel sheep. African Journal of Biotechnology Vol. 8 (12): 2903-2907

Nawaz M and Khalil AM 1998 Comparison of Lohi and crossbred ewes: Productive traits. Small Ruminant Research 27:223-229.

Rashidi A, Mokhtari MS, Safi Jahanshahi A, Mohammad Abadi M.R 2008 Genetic parameter estimates of pre-weaning growth traits in Kermani sheep. Small Rumin. Res. 74: 165-171.

Rastogi RK. 2001 Production performance of Barbados black sheep in Tabago, West Indies. Small Ruminant research 41:171-175.

RIM. 1992 Resource Inventory Management Ltd. Nigerian Livestock Survey. Federal Department of Livestock pest control services, Abuja. 287pp.

SAS 2001 SAS User's Guide: Statistics, Statistical Analysis System Institute, Inc. Cary, NC.

Taiwo BBA, Ngere LO, Adebayo IOA 1992 Comparative growth performance of Nigerian dwarf sheep and its crosses with Permer, Uda one stage or the other. Therefore, effects of nongenetic factors need to be corrected for if mixed model approaches such as the Best Linear Unbiased Prediction (BLUP) values are to be used for breeding value evaluation in Balami and Uda lambs.

and Yankasa. World Review of Animal Production 18:57-63.

Wilson RT 1986 Productivity of traditionally managed small ruminants in agro-pastoral system in North Burkina Faso. Tropical Agriculture (Trinidad) 64:163-169. 